\title{
Pattern of Activated Pathways and Quality of Collateral Status in Patients with Symptomatic Internal Carotid Artery Occlusion
}

\author{
Florian Connolly ${ }^{a}$ Jens E. Röhl ${ }^{b}$ Javier Lopez-Prieto ${ }^{c}$ Leon A. Danyel ${ }^{a}$ \\ Stephan J. Schreiber ${ }^{d}$ Jose M. Valduezac \\ ${ }^{a}$ Department of Neurology, University Hospital Charité, Berlin, Germany; ${ }^{b}$ Department of Neurology, Ernst von \\ Bergmann Klinikum, Potsdam, Germany; ' Neurological Center, Segeberger Kliniken, Bad Segeberg, Germany; \\ ${ }^{\mathrm{d}}$ Department of Neurology, Asklepios Fachklinikum Brandenburg, Brandenburg, Germany
}

\section{Keywords}

Carotid artery occlusion · Collaterals · Transcranial color-coded sonography $\cdot$ Cerebral hemodynamics

\begin{abstract}
Background: Internal carotid artery occlusion (ICAO) is an important risk factor for stroke. Cerebral hemodynamics in patients with ICAO depends on the individual capacity to activate sufficient collateral pathways. Therefore, the assessment of intracranial collaterals is essential for the acute and long-term management of these patients and accurate estimation of further stroke risk. Methods: Acute stroke patients with unilateral ICAO were prospectively enrolled. We assessed the following collaterals by transcranial color-coded sonography (TCCS): the anterior and posterior communicating artery $(A C O A, P C O A)$, the ophthalmic artery $(O A)$, and leptomeningeal collaterals of the posterior cerebral artery (LMC). We subdivided the flow pattern of the Doppler spectrum in the middle cerebral artery (MCA) into 3 categories: (1) good, (2) moderate, and (3) bad according to the hemodynamic effects on the ipsilateral MCA flow. Finally, we compared the individual TCCS results with the stroke pattern detected on CT or MRI scan. Results: One hundred thirteen patients (age $66 \pm 12$ years; female 24) were included. The collateral status was good, moderate, and bad in 59 (52\%),
\end{abstract}

37 (33\%), and 17 (15\%) patients, respectively. The ACoA collateral was most frequently activated $(81 \%)$, followed by the OA (63\%), the PCoA (53\%), and the LMC (22\%). The quality of the collateral status was determined by the type $(p=0.0003)$ but not by the number $(p=0.19)$ of activated collateral pathways. Good collateral function was highly associated with primary collaterals (ACoA > PCOA). Best parameter for a good collateral status was an antegrade flow in the $O A$, indicating a high blood supply via the communicating arteries. Conclusions: TCCS allows the assessment of intracranial collaterals and their hemodynamic capacity. Prevalence of collateral sufficiency in ICAO seems to be higher than previously reported. ACoA cross flow is essential for the optimal hemodynamic compensation of ICAO. Antegrade OA flow indicates good collateral status.

๑) 2019 S. Karger AG, Basel

\section{Introduction}

Extracranial internal carotid artery occlusion (ICAO) is mostly of arteriosclerotic origin and associated with an increased risk of stroke and retinal ischemia. The overall incidence of ICAO is unknown, whereas the incidence of symptomatic unilateral ICAO is $6 / 100,000$ [1]. The annual stroke risk in symptomatic patients is about $5 \%$, but

\section{KARGER}

(C) 2019 S. Karger AG, Basel

E-Mail karger@karger.com

www.karger.com/ced
Florian Connolly, MD

Department of Neurology

Charité Universitätsmedizin Berlin

Augustenburger Platz 1, DE-13344 Berlin (Germany)

E-Mail florian.connolly@charite.de 
increases up to $40 \%$ in patients with severe impairment of cerebral hemodynamics [2]. Mechanism of stroke in ICAO is embolic and hemodynamic. Embolic infarctions typically occur in cases of acute ICAO, whereas hemodynamic constraint is the main cause of stroke (ischemia) in patients with chronic ICAO [3]. Reduced perfusion in the border zones between the vascular territories may result in hemodynamic infarctions (border zone infarcts, BZI) [4-6].

The nature of cerebral hemodynamics in patients with ICAO depends mainly on the individual capacity to activate alternative pathways, which is particularly determined by the anatomy of the circle of Willis (CW) [7-10].

Four intracranial collateral pathways can be distinguished and further subdivided in primary and secondary collaterals. The former include a cross flow via the anterior communicating artery $(\mathrm{ACoA})$ and an activated flow via the posterior communicating artery ( $\mathrm{PCoA}$ ) from the posterior circulation, the latter a retrograde flow in the ophthalmic artery (OA) and leptomeningeal collaterals via PCA branches (LMC) [11].

Exact knowledge about the individual collateral status and its capacity to ensure a stable cerebral blood flow in stroke patients are essential for optimal acute stroke unit management, determination of long-term blood pressure treatment, and assessment of individual patient outcome.

Transcranial color-coded sonography (TCCS) is an exceptionally suitable method to assess extra- and intracranial alternative pathways, as it allows the noninvasive visualization of the cerebral hemodynamic. In particular, it is a unique method to visualize and quantify OA flow.

Therefore, the aim of this TCCS study was to analyze the composition of cerebral collaterals in ICAO patients. We further assessed the quality of collateral flow, as well as the stroke subtypes associated with specific collateral patterns.

\section{Materials and Methods}

We prospectively enrolled patients with symptomatic unilateral ICAO admitted to our stroke and rehabilitation centers. ICAO was diagnosed using extracranial color-coded duplex-sonography (7-11 MHz linear transducer, Toshiba Aplio 300 or $9 \mathrm{MHz}$ linear transducer, GE LOGIQ S7). Diagnostic criteria for ICAO were a missing color mode and Doppler flow signal despite delineated vessel walls and optionally, a stump signal at the origin of the ICA. TCCS was performed with a $2.5 \mathrm{MHz}$ sector-array transducer of the same ultrasound system. The MCA, ICA, anterior cerebral artery (ACA), posterior cerebral artery (PCA), ACoA, and PCoA were analyzed via the transtemporal approach, and the OA was assessed using the transorbital approach.

Collateral Pathways in Carotid Artery Occlusion

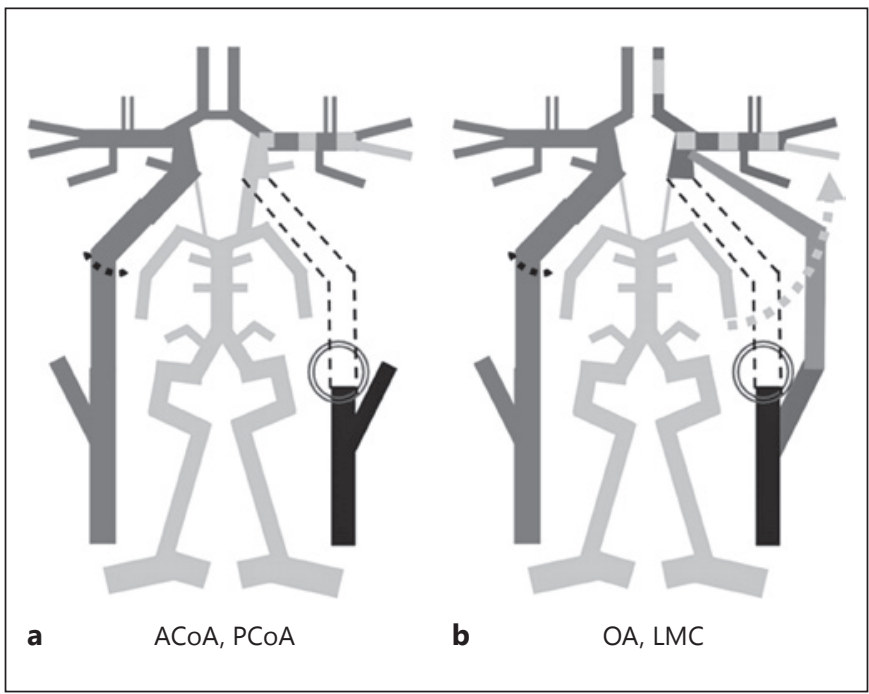

Fig. 1. Schematic of the 4 main intracranial collateral pathways in patients with unilateral extracranial ICA occlusion. a Via the ACoA and PCoA. $\mathbf{b}$ Via the retrograde OA and leptomeningeal of the PCA. Number and type of activated collaterals depend on the individual anatomy of the CW. ACoA, anterior communicating artery; PCoA, posterior communicating artery; OA, ophthalmic artery; LMC, leptomeningeal collaterals.

The following collateral pathways were assessed: ACoA and PCoA as primary and retrograde OA and LMC of the PCA as secondary collaterals (Fig. 1).

The diagnostic criteria were as follows: (i) ACoA collateral: retrograde flow in the ipsilateral A1-ACA [12], (ii) PCoA collateral: blood flow velocity in the P1-PCA higher than in the P2-PCA as well as in the contralateral P1-PCA and optionally a visible PCoA with a blood flow direction towards the ICA $[12,13]$, (iii) OA collateral: retrograde blood flow in the OA [14], and (iv) LMC of the PCA collateral: blood flow velocity in the P1- and P2-PCA exceeds the contralateral side of at least $>30 \%$ and is higher than in the contralateral MCA $[10,15]$.

The Doppler spectrum of the ipsilateral MCA was divided by eyeball estimation into 5 subgroups: (i) normal flow pattern, (ii) mild, (iii) moderate, (iv) severe, and (v) pseudo-venous poststenotic flow pattern depending on the delay of the systolic acceleration time and the decrease to pulsatility (Fig. 2) [11]. The quality of collateral status was then evaluated through the MCA flow pattern and further classified into 3 categories: good (normal or mild poststenotic flow pattern), moderate, and bad (severe or pseudovenous poststenotic flow pattern).

Patients with an insufficient transtemporal bone window for TCCS analysis, stenosis $>50 \%$ or occlusion of the ipsilateral external carotid artery, the contralateral common carotid artery or ICA, and any vertebral artery or basal cerebral artery were excluded.

We evaluated the stroke etiology according to their pattern on CCT or MRI scan. BZI (hemodynamic stroke) were distinguished from territorial or lacunar infarctions (nonhemodynamic stroke), and the quality of the collateral status according to the MCA flow pattern was compared between these 2 groups. 
Fig. 2. Normal (1), mild (2), moderate (3), severe (4), and pseudovenous (5) poststenotic flow pattern in the MCA. Defined quality of collateral status: good: (1) and (2), moderate (3), bad: (4) and (5).

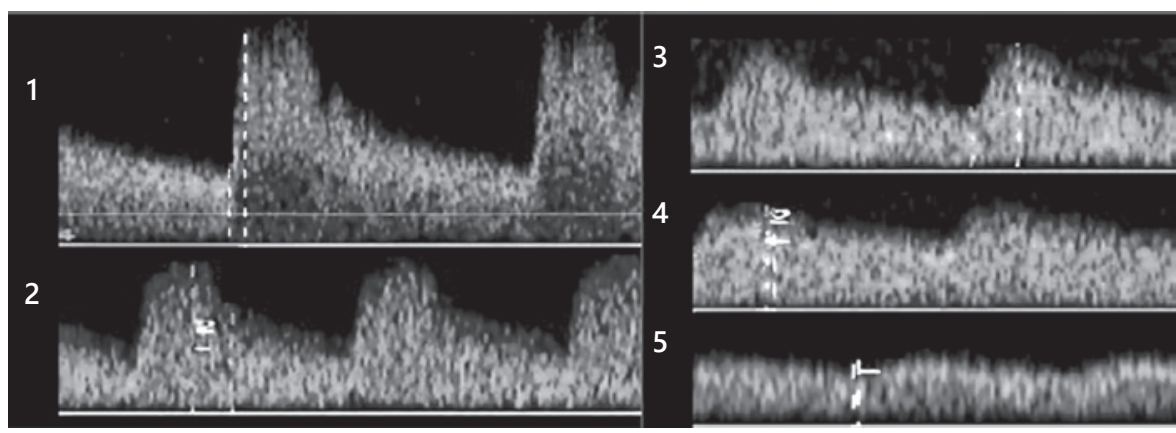

The study was approved by the local Ethics Committee, and informed consent was obtained from all patients.

\section{Statistics}

Descriptive statistics are presented as the mean \pm SD. A $p$ value of $<0.05$ was considered statistically significant. Chi-square test was used for the following comparative analyses:

1. Stroke type (hemodynamic vs. nonhemodynamic stroke) and collateral status (MCA flow pattern good vs. moderate or bad)

2. OA flow direction (antegrade, retrograde, or no flow) and MCA flow pattern (good, moderate, or bad)

3. Quantity of activated collaterals and MCA flow pattern

4. Type of collateral pathway (ACoA, PCoA, OA, or LMC) and MCA flow pattern

5. OA flow direction and activated PCoA collateral (yes or no)

\section{Results}

One hundred thirteen patients (age $66 \pm 12$ years; female: 24) with unilateral extracranial ICA occlusion were prospectively enrolled in the study.

A good, moderate, and bad collateral status according to the ipsilateral MCA flow pattern were observed in 59 (52\%), 37 (33\%), and 17 (15\%) patients, respectively.

The total number of collateral pathways was as follows: ACoA 92 (81\%), OA 71 (63\%), PCoA 60 (53\%), and LMC $25(22 \%)$. Most patients activated $2(n=62 ; 55 \%)$ or $3(n=29 ; 26 \%)$ collaterals, whereas only one or all 4 pathways were found in $17(15 \%)$ and $5(4 \%)$ subjects, respectively (Table 1). No relationship was found between the number of activated collaterals and the blood flow pattern in the MCA $(p=0.19)$.

Almost all patients (58 of 59) with a good collateral function revealed a cross flow via the ACoA (sensitivity 98\%, NPV 97\%, and PPV 63\%; Fig. 3). PCoA and OA collaterals did not show closer relation to a specific MCA flow pattern, whereas the LMC was mainly activated in patients with moderate (in $30 \%$ ) or bad (in $47 \%$ ) collateral status (Table 2). All patients with a good collateral status exhib-
Table 1. Relationship between quantity of activated collateral pathways and the blood flow pattern in the MCA

Number of patients with the different quantity of activated collaterals (\%)

$\begin{array}{lll}\text { Blood flow } & \text { pattern in the MCA } \\ \begin{array}{lll}\text { good } & \text { moderate } & \text { bad } \\ (n=59) & (n=37) & (n=17)\end{array}\end{array}$

One collateral: $n=17(15)$

Two collaterals: $n=62(55)$

Three collaterals: $n=29$ (26)

Four collaterals: $n=5$ (4)

11
30

11
30

16

16
2

MCA, middle cerebral artery. ited at least one primary collateral. The type of activated collateral pathway (ACoA, PCoA, OA, LMC) determined the MCA flow pattern significantly $(p=0.0003)$.

An antegrade OA was found in 27 patients (24\%) and associated with an activated PCoA in $19(70 \%)$ and $\mathrm{ACoA}$ in $25(93 \%)$ cases, whereas in patients with retrograde $(n=$ $71 ; 63 \%)$ or missing OA flow $(n=15 ; 13 \%)$, a PCoA collateral was observed only in $48 \%$ of cases $(n=41 ; p=0.05)$. Antegrade OA indicated good collateral status (23/27: PPV $85 \%)$, whereas a retrograde OA was often found in a bad $(11 / 17$ or $65 \%)$ collateral status ( $p=0.0002$; Fig. 4$)$.

In 94 out of 113 patients, a reliable classification of stroke etiology by CT or MRI stroke pattern was accomplished. Sixteen patients showed a BZI pattern, whereas 55 patients revealed an embolic or lacunar stroke pattern. Furthermore, 23 patients with TIA had no ischemic stroke on neuroimaging, whereas no distinct classification of stroke etiology was feasible in the remaining 19 patients. Patients with BZI more frequently exhibited a moderate (56\%) or bad $(25 \%)$ collateral status when compared with patients of embolic or lacunar stroke (33 and 20\%, respectively; $p=0.03$ ). In patients without observable acute stroke pattern, however, a good, moderate, or bad collateral status was found in 61,30 , and $9 \%$ of cases, respectively. 


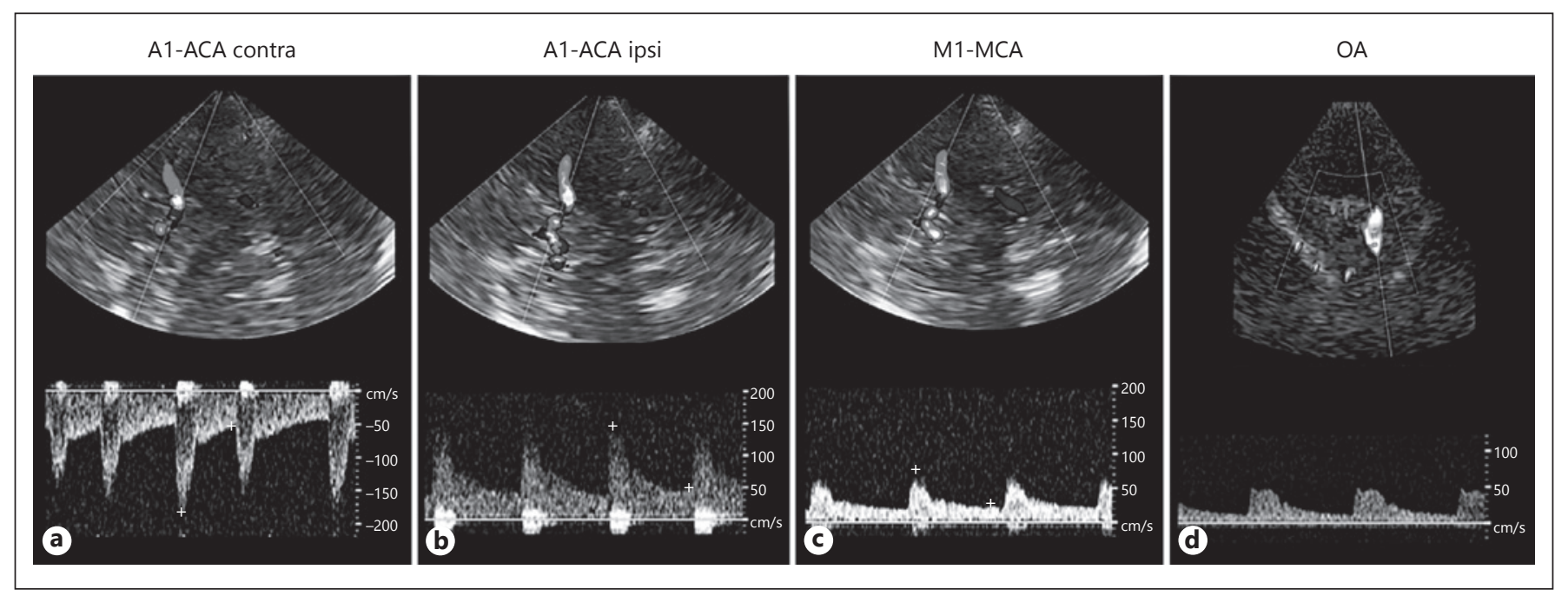

Fig. 3. Intracranial collateral pathways in a 64-year-old man with left-sided ICA occlusion and good collateral status. a Increased flow in the right A1-ACA. b Retrograde flow in the left A1-ACA. c Normal flow pattern in the left MCA. d Antegrade flow in the left OA (transorbital approach). ACA, anterior cerebral artery; MCA, middle cerebral artery; OA, ophthalmic artery.
Table 2. Relationship between the type of collateral pathway and the blood flow pattern in the MCA

\begin{tabular}{|c|c|c|c|}
\hline \multirow{2}{*}{$\begin{array}{l}\text { Type of collateral pathway } \\
\text { and number of patients, } n\end{array}$} & \multicolumn{3}{|c|}{ Blood flow pattern in the MCA } \\
\hline & $\begin{array}{l}\text { good } \\
(n=59), \\
n(\%)\end{array}$ & $\begin{array}{l}\text { moderate } \\
(n=37), \\
n(\%)\end{array}$ & $\begin{array}{l}\text { bad } \\
(n=17), \\
n(\%)\end{array}$ \\
\hline $\mathrm{ACoA}(n=92)$ & $58(98)$ & $29(78)$ & $5(29)$ \\
\hline $\operatorname{PCoA}(n=60)$ & $36(61)$ & $16(43)$ & $8(47)$ \\
\hline $\mathrm{OA}(n=71)$ & $27(46)$ & $33(89)$ & $11(65)$ \\
\hline $\operatorname{LMC}(n=25)$ & $6(10)$ & $11(30)$ & $8(47)$ \\
\hline
\end{tabular}

ACoA, anterior communicating artery; PCoA, posterior communicating artery; OA, ophthalmic artery; LMC, leptomeningeal collaterals; MCA, middle cerebral artery.

\section{Discussion}

Intracranial collateral pathways are an essential safety mechanism for the prevention and attenuation of ischemic stroke. Moreover, they determine the long-term prognosis of patients with chronic artery occlusion [16, 17]. For example, the incidence of BZI due to ICAO is significantly lower in patients with sufficient PCoA collateral function [18]. Collateral insufficiency impairs cerebrovascular reactivity (CVR) and aggravates the risk of subsequent TIA and stroke [19-21]. The general annual stroke risk in symptomatic ICAO is approximately

Collateral Pathways in Carotid Artery Occlusion
$5 \%$, but increases up to 12 and $41 \%$ in patients with impaired or exhausted CVR $[2,22]$. Our results underline the importance of cerebral collateralization as patients with BZI exhibited a significantly higher incidence of moderate or bad collateral status.

Formation of collateral pathways and collateral quality depend on the individual anatomy of the CW. However, a complete and therefore fully functional CW exists only in approximately $30 \%$ of elderly (arteriosclerotic) patients, which limits the collateral pathway options in many patients to compensate ICAO [8]. A threshold diameter of $0.4-0.6 \mathrm{~mm}$ was found for a sufficient collateral function of the ACoA and PCoA [7].

TCCS is a very suitable noninvasive technique to evaluate cerebral collaterals as it permits a direct and realtime evaluation of the hemodynamic effects of ICAO and provides distinct identification criteria for all relevant collateral pathways. An ipsilateral retrograde A1-ACA flow reveals an ACoA cross flow with excellent sensitivity (98\%) and specificity (100\%), compared to conventional angiography [12]. Likewise, the TCCS criteria for PCoA collateral activation yield high sensitivity $(84 \%)$ and specificity (94\%) in comparison to DSA [12]. Moreover, retrograde OA flow can be considered a specific sign for ICAO or high-graded stenosis [14, 23, 24].

Varying TCCS criteria, however, were proposed for PCA-LMC activation. Using a cutoff criterion of a PSV $>100 \mathrm{~cm} / \mathrm{s}$ yielded a diagnostic sensitivity of $77 \%$ and specificity of $83 \%$ in comparison to DSA [25]. Further 


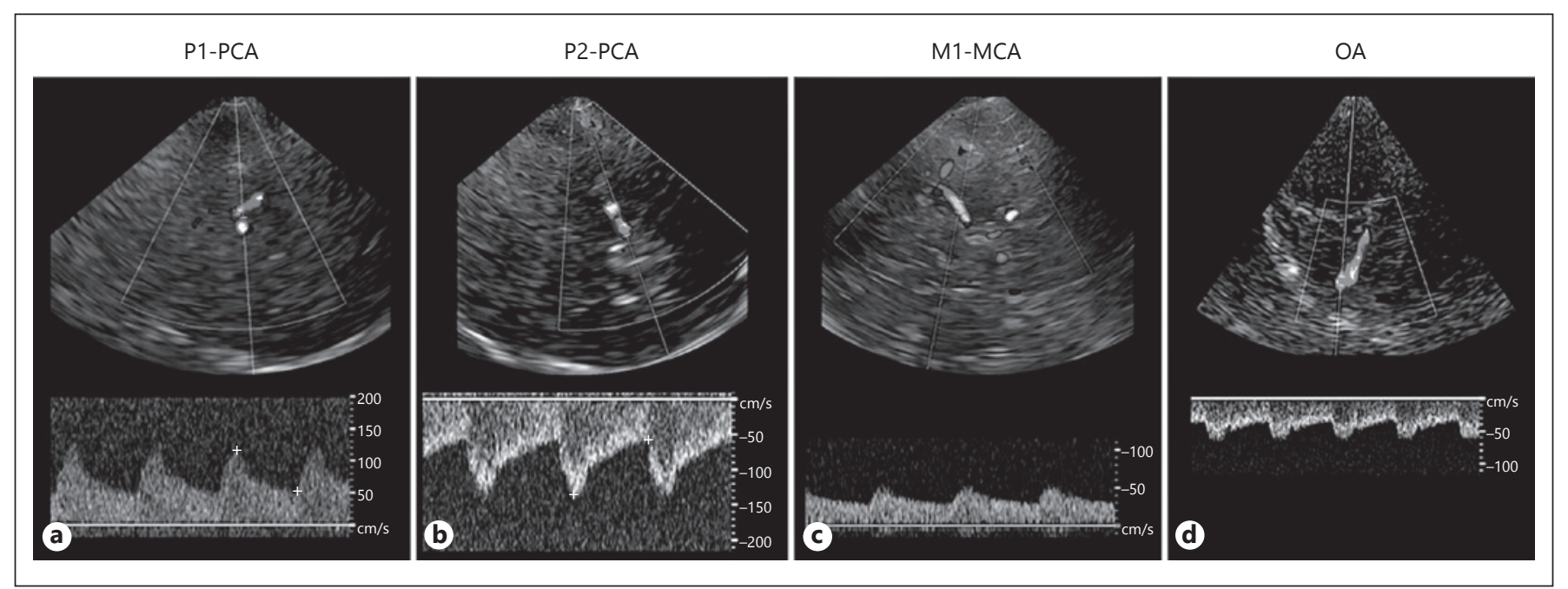

Fig. 4. Intracranial collateral pathways in a 72-year-old man with left-sided ICA occlusion and bad collateral status. a Increased flow in the left P1-PCA. b Increased flow in the P2-PCA. c Severe post- stenotic flow in the left MCA. d Retrograde flow in the left OA (transorbital approach). PCA, posterior cerebral artery; MCA, middle cerebral artery; OA, ophthalmic artery. criteria indicating PCA-LMC activation have been reported by different authors, for example, a PCA asymmetry index $>28 \%$ [15] or a PCA flow velocity equal to or higher than the contralateral MCA [10].

In this study, we used a pragmatic definition system to assess collateral status quality in ICAO. Blood flow velocity and pulsatility in the ipsilateral MCA depend mainly on the amount of collateral blood flow. A reduced flow in the case of collateral insufficiency results in a compensatory dilatation of resistance vessels with subsequent reduction of peripheral resistance causing a raised diastolic flow component and reduced pulsatility. However, our grading of the MCA Doppler spectrum with 5 different degrees according to the visual appearance is not well established until now. A more time-consuming indirect method to assess the functioning of the activated collaterals is the analysis of the CVR by transcranial Doppler.

Fifty-two percent of our patients with ICAO exhibited a good quality of cerebral collateral flow, whereas only in $15 \%$ an insufficient quality of collateral status was observed. This challenges previous findings, reporting poststenotic flow pattern in $67-80 \%$ in ICAO or high-graded ICA stenosis [26, 27].

\section{Primary Collaterals}

It is not the absolute number but the type of activated collaterals that determines the quality of the collateral function. The primary collaterals were more frequently activated than the secondary collaterals and were present in every patient with good collateral function. On the other hand, none of our patients with exclusive secondary collateral activation had a normal MCA Doppler spectrum. The ACoA collateral was significantly more often activated and associated with a good collateral status than the PCoA collateral. Compared to the literature, our study found higher prevalence of ACoA "cross flow" in ICAO, while PCoA activation was observed at a lower rate, than previously reported $[26,28]$. Our findings support the notion of a higher capacity of the contralateral anterior circulation to compensate ICAO, when compared to the posterior circulation and an overall higher incidence of impairment in collateral function for the P1PCA and PCoA compared to the A1-ACA and ACoA [8, 9]. However, the presence of primary collaterals does not guarantee good collateral status quality. ACoA and PCoA collaterals were activated in 29 and $47 \%$ of patients with severe or pseudovenous poststenotic flow patterns in the MCA. A diameter of the communicating arteries or of the depending A1-ACA and P1-PCA below the threshold mentioned above might be the reason in these cases [7].

\section{Secondary Collaterals}

The OA and LMC are considered as second-order collaterals serving as a reserve system if the first-line collaterals are insufficient. However, we observed a retrograde OA in 71 patients $(63 \%)$ of which $46 \%$ exhibited a good collateral status due to the additional activation of primary collaterals. This challenges previous findings that 
retrograde OA flow is associated with an absence of primary collaterals and generally indicates an insufficient collateral status $[29,30]$.

An antegrade OA was found in $24 \%$ of our patients, comparable to previous data [14]. In these cases, the OA filling results from the communicating arteries, via the PCoA (70\%) or the ACoA (93\%). This may be explained by the close spatial relationship between the PCoA and $\mathrm{OA}$ ostium of the ICA. The strong association between antegrade OA flow and good collateral status in $85 \%$ of our patients confirms once more the superior quality of the primary collaterals. Vice versa, the frequent finding of retrograde OA perfusion in patients with moderate and severe or pseudovenous flow pattern in the MCA verifies its limited capacity to compensate ICAO.

We observed PCA-LMC only in a minority of our patients (22\%), usually associated with moderate or bad collateral status. A high interindividual variability of LMC activation was described previously [31], with restricted collateral capacity in stroke patients of high age and with metabolic syndrome, probably due to the increased vessel wall rigidity $[32,33]$. Furthermore, a fetal-type PCA impedes LMC activation, which occurs in approximately $10 \%$ of all patients $[34,35]$. It appears reasonable that a marked LMC of the PCA is not able to secure the perfusion of the ipsilateral anterior circulation. Therefore, we detected a severe poststenotic MCA flow pattern in $47 \%$ of our patients exhibiting PCA-LMC.

\section{Limitations of the Study}

A crucial point is the eyeball estimation of the poststenotic MCA flow pattern to evaluate the sufficiency of the collateral status. This might lead to a certain subjectivity as no validated definition criteria for this method have been established. The PI or the systolic acceleration time might be more objective and reliable to assess the hemodynamic state in patients with ICA-occlusion. However, even for these parameters, no generally accepted cutoff values to differentiate between normal and poststenotic blood flow patterns exist so far.

\section{Conclusions}

In summary, our findings illustrate that the quality of collateral status varies widely in patients with ICAO and rather depends on the type of collateral than on the number of activated collateral pathways. A sufficient cross flow via the ACoA is essential for a good collateral function. While antegrade $\mathrm{OA}$ is the best predictor for a good collateral status in ICAO, indicating a sufficient function of the primary collaterals, activation of LMC is more likely to imply a critical hemodynamic state. Finally, our study confirms the higher risk for hemodynamic stroke in ICAO patients with compromised collateral status, which can easily be assessed by TCCS.

\section{Disclosure Statement}

The authors have no conflicts of interest to disclose.

\section{Funding Sources}

The study was funded by Stiftung Charité in the context of the Berlin Institute of Health Clinical Fellowship.

\section{References}

1 Flaherty ML, Flemming KD, McClelland R, Jorgensen NW, Brown RD Jr. Populationbased study of symptomatic internal carotid artery occlusion: incidence and long-term follow-up. Stroke. 2004 Aug;35(8):e349-52.

2 Klijn CJ, Kappelle LJ, Tulleken CA, van Gijn J. Symptomatic carotid artery occlusion. A reappraisal of hemodynamic factors. Stroke. 1997 Oct;28(10):2084-93.

3 Pessin MS, Hinton RC, Davis KR, Duncan GW, Roberson GH, Ackerman RH, et al. Mechanisms of acute carotid stroke. Ann Neurol. 1979 Sep;6(3):245-52.

4 Weiller C, Ringelstein EB, Reiche W, Buell U. Clinical and hemodynamic aspects of lowflow infarcts. Stroke. 1991 Sep;22(9):111723.

Collateral Pathways in Carotid Artery Occlusion
5 Baumgartner RW, Regard M. Role of impaired $\mathrm{CO} 2$ reactivity in the diagnosis of cerebral low flow infarcts. J Neurol Neurosurg Psychiatry. 1994 Jul;57(7):814-7.

6 Hupperts RM, Lodder J, Heuts-van Raak EP, Wilmink JT, Kessels AG. Borderzone brain infarcts on CT taking into account the variability in vascular supply areas. Cerebrovasc Dis. 1996;6(5):294-300.

7 Hoksbergen AW, Fülesdi B, Legemate DA, Csiba L. Collateral configuration of the circle of Willis: transcranial color-coded duplex ultrasonography and comparison with postmortem anatomy. Stroke. 2000a Jun;31(6):1346-51.

8 Hoksbergen AW, Legemate DA, Ubbink DT, Jacobs MJ. Collateral variations in circle of willis in atherosclerotic population assessed by means of transcranial color-coded duplex ultrasonography. Stroke. 2000b Jul;31(7): 1656-60.

9 Hoksbergen AW, Legemate DA, Csiba L, Csáti G, Síró P, Fülesdi B. Absent collateral function of the circle of Willis as risk factor for ischemic stroke. Cerebrovasc Dis. 2003;16(3):191-8.

10 Kim YS, Meyer JS, Garami Z, Molina CA, Pavlovic AM, Alexandrov AV. Flow diversion in transcranial Doppler ultrasound is associated with better improvement in patients with acute middle cerebral artery occlusion. Cerebrovasc Dis. 2006;21(1-2):74-8.

11 Valdueza JM, Schreiber SJ, Roehl JE, Connolly F, Klingebiel R. Neurosonology and neuroinaging of stroke. 2nd ed. Stuttgart: Thieme; 2017.

\section{Occlusion}


12 Baumgartner RW, Baumgartner I, Mattle HP, Schroth G. Transcranial color-coded duplex sonography in the evaluation of collateral flow through the circle of Willis. AJNR Am J Neuroradiol. 1997 Jan;18(1):127-33.

13 Baumgartner RW, Baumgartner I, Mattle HP, Schroth G. Transcranial color-coded duplex sonography in unilateral flow-restrictive extracranial carotid artery disease. AJNR Am J Neuroradiol. 1996 Apr;17(4):777-83.

14 Reynolds PS, Greenberg JP, Lien LM, Meads DC, Myers LG, Tegeler CH. Ophthalmic artery flow direction on color flow duplex imaging is highly specific for severe carotid stenosis. J Neuroimaging. 2002 Jan;12(1):5-8.

15 Zanette EM, Roberti C, Mancini G, Pozzilli C, Bragoni M, Toni D. Spontaneous middle cerebral artery reperfusion in ischemic stroke. A follow-up study with transcranial Doppler. Stroke. 1995 Mar;26(3):430-3.

16 Liebeskind DS, Cotsonis GA, Saver JL, Lynn MJ, Turan TN, Cloft HJ, et al.; Warfarin-Aspirin Symptomatic Intracranial Disease (WASID) Investigators. Collaterals dramatically alter stroke risk in intracranial atherosclerosis. Ann Neurol. 2011 Jun;69(6):963-74.

17 Miteff F, Levi CR, Bateman GA, Spratt N, McElduff P, Parsons MW. The independent predictive utility of computed tomography angiographic collateral status in acute ischaemic stroke. Brain. 2009 Aug; 132(Pt 8): 2231-8.

18 Hendrikse J, Hartkamp MJ, Hillen B, Mali WP, van der Grond J. Collateral ability of the circle of Willis in patients with unilateral internal carotid artery occlusion: border zone infarcts and clinical symptoms. Stroke. 2001 Dec;32(12):2768-73.

19 Kleiser B, Widder B. Course of carotid artery occlusions with impaired cerebrovascular reactivity. Stroke. 1992 Feb;23(2):171-4.
20 Blaser T, Hofmann K, Buerger T, Effenberger O, Wallesch CW, Goertler M. Risk of stroke, transient ischemic attack, and vessel occlusion before endarterectomy in patients with symptomatic severe carotid stenosis. Stroke. 2002 Apr;33(4):1057-62.

21 Reinhard M, Schwarzer G, Briel M, Altamura C, Palazzo P, King A, et al. Cerebrovascular reactivity predicts stroke in high-grade carotid artery disease. Neurology. 2014 Oct;83(16): 1424-31.

22 Klijn CJ, Kappelle LJ, van Huffelen AC, Visser GH, Algra A, Tulleken CA, et al. Recurrent ischemia in symptomatic carotid occlusion: prognostic value of hemodynamic factors. Neurology. 2000 Dec;55(12):1806-12.

23 Nuzzaci G, Righi D, Borgioli F, Nuzzaci I, Giannico G, Pratesi C, et al. Duplex scanning exploration of the ophthalmic artery for the detection of the hemodynamically significant ICA stenosis. Stroke. 1999 Apr;30(4): 821-6.

24 Saqqur M, Demchuk AM, Hill MD, Dean N Schebel M, Kennedy J, et al. Bedside emergency transcranial Doppler diagnosis of severe carotid disease using orbital window examination. J Neuroimaging. 2005 Apr;15(2): $138-43$.

25 Kimura K, Minematsu K, Yasaka M, Wada K, Yamaguchi T. Evaluation of posterior cerebral artery flow velocity by transcranial colorcoded real-time sonography. Ultrasound Med Biol. 2000 Feb;26(2):195-9.

26 Demchuk AM, Christou I, Wein TH, Felberg RA, Malkoff M, Grotta JC, et al. Specific transcranial Doppler flow findings related to the presence and site of arterial occlusion. Stroke. 2000b Jan;31(1):140-6

27 Hartmann A, Mast H, Thompson JL, Sia RM, Mohr JP. Transcranial Doppler waveform blunting in severe extracranial carotid artery stenosis. Cerebrovasc Dis. 2000 Jan-Feb; 10(1):33-8.

28 Henderson RD, Eliasziw M, Fox AJ, Rothwell PM, Barnett HJ; North American Symptomatic Carotid Endarterectomy Trial (NASCET) Group. Angiographically defined collateral circulation and risk of stroke in patients with severe carotid artery stenosis. Stroke. 2000 Jan;31(1):128-32.

29 Schneider PA, Rossman ME, Bernstein EF, Ringelstein EB, Otis SM. Noninvasive assessment of cerebral collateral blood supply through the ophthalmic artery. Stroke. 1991 Jan;22(1):31-6.

30 Hofmeijer J, Klijn CJ, Kappelle LJ, Van Huffelen AC, Van Gijn J. Collateral circulation via the ophthalmic artery or leptomeningeal vessels is associated with impaired cerebral vasoreactivity in patients with symptomatic carotid artery occlusion. Cerebrovasc Dis. 2002;14(1):22-6.

31 Liebeskind DS. Collateral circulation. Stroke. 2003 Sep;34(9):2279-84

32 Brozici M, van der Zwan A, Hillen B. Anatomy and functionality of leptomeningeal anastomoses: a review. Stroke. 2003 Nov;34(11):2750-62.

33 Menon BK, Smith EE, Coutts SB, Welsh DG, Faber JE, Goyal M, et al. Leptomeningeal collaterals are associated with modifiable metabolic risk factors. Ann Neurol. 2013 Aug; 74(2):241-8.

34 Jongen JC, Franke CL, Soeterboek AA, Versteege CW, Ramos LM, van Gijn J. Blood supply of the posterior cerebral artery by the carotid system on angiograms. J Neurol. 2002 Apr;249(4):455-60.

35 van der Lugt A, Buter TC, Govaere F, Siepman DA, Tanghe HL, Dippel DW. Accuracy of CT angiography in the assessment of a fetal origin of the posterior cerebral artery. Eur Radiol. 2004 Sep;14(9):1627-33. 